\title{
A brief communication on the effect of seawater on water flow in offshore wells at supercritical state
}

\author{
Fengrui Sun ${ }^{1,2,3} \cdot$ Yuedong $\mathrm{Yao}^{1,2,3} \cdot$ Xiangfang $\mathrm{Li}^{2,3} \cdot$ Guozhen $\mathrm{Li}^{4}$
}

Received: 15 October 2017 / Accepted: 3 April 2018 / Published online: 12 April 2018

(c) The Author(s) 2018

\begin{abstract}
At present, the study of supercritical water (SCW) flow in wellbores is at the starting stage. In this paper, a simple but useful model is developed to study the effect of seawater on the thermophysical properties of SCW in offshore vertical wellbores. Firstly, based on the momentum and energy balance equations, a flow model describing SCW flow in a tube is established. Then, coupled with transient heat transfer model in seawater and formation, and thermophysical parameters of SCW, a comprehensive mathematical model is established. In order to solve the model, the governing equations are expressed in the form of difference equations. The straight forward numerical method is adopted to solve the model from wellhead to well-bottom. In the process of solving, iterative technique is used to control the calculation accuracy. Finally, type curves of SCW flow in offshore wellbores and sensitivity analysis are discussed. Results show that (a) the flow of seawater results in a rapid decline in the temperature/enthalpy of SCW in wellbores. (b) Heat loss is the dominant factor of physical parameter distribution in wellbores when the injection rate is relatively small. (c) Heat loss has an obvious influence on temperature drop when SCW is sparse in volume. (d) The SCW pressure decreases with increasing of injection temperature.
\end{abstract}

Keywords Heavy oil recovery $\cdot$ Wellbore modeling $\cdot$ Supercritical water $\cdot$ Effect of seawater $\cdot$ Heat loss rate $\cdot$ Injection parameters

\author{
List of symbols \\ $w_{\mathrm{SCW}}$ The mass flow rate of SCW in offshore wells \\ $(\mathrm{kg} / \mathrm{s})$ \\ $r_{a i} \quad$ The inner radius of the inner tubing (m) \\ $\rho_{\text {SCW }}$ The density of SCW $\left(\mathrm{kg} / \mathrm{m}^{3}\right)$ \\ $v_{\mathrm{SCW}}$ The flow velocity of SHS $(\mathrm{m} / \mathrm{s})$ \\ $z \quad$ The well depth (m)
}

Fengrui Sun

13126682711@163.com

$\triangle$ Yuedong Yao

yaoyuedong@163.com

1 State Key Laboratory of Petroleum Resources and Prospecting, China University of Petroleum - Beijing, Beijing 102249, People's Republic of China

2 College of Petroleum Engineering, China University of Petroleum - Beijing, Beijing 102249, People's Republic of China

3 Laboratory for Petroleum Engineering of the Ministry of Education, China University of Petroleum - Beijing, Beijing 102249, People's Republic of China

4 China University of Petroleum - Beijing, Beijing 102249, People's Republic of China
$Q_{\mathrm{SCW}}$ The heat transfer rate from SCW to seawater/formation $(\mathrm{J} / \mathrm{s})$

$h_{\text {SCW }}$ The specific enthalpy of SCW $(\mathrm{J} / \mathrm{kg})$

$g \quad$ The gravitational acceleration $\left(\mathrm{m} / \mathrm{s}^{2}\right)$

$\theta \quad$ The well angle from vertical (rad)

$f \quad$ The shear force in the vertical wellbores (N)

\section{Introduction}

Thermal energy is widely adopted in engineering (Sheikholeslami et al. 2013, 2017, 2018; Sheikholeslami and Ganji 2014, 2016; Sheikholeslami and Bhatti 2017; Sheikholeslami and Rokni 2017a, b, 2018; Sheikholeslami and Sadoughi 2017, 2018; Sheikholeslami and Seyednezhad 2017, 2018; Sheikholeslami and Shehzad 2017a, b, 2018a, b, c). In the petroleum industry, the recovery of heavy oil can be mainly divided into two types: thermal recovery (Dong et al. 2015; Rego et al. 2017; Nian and Cheng 2017; Mullakaev et al. 2017; Akhmedzhanov et al. 2017; Telmadarreie and Trivedi 2017) and the cold recovery (Coskuner et al. 2015; Zhou et al. 2018). The thermal recovery is mainly conducted by injecting thermal fluid (e.g., wet steam, superheated steam, 
multi-component thermal fluid) into oil layers (Marx and Langenheim 1959; Sun et al. 2017a). This is because the viscosity of heavy oil is extremely sensitive to temperature. A small increase in temperature can cause great drop of viscosity of heavy oil. One may find that when these thermal methods are adopted, the heat loss estimation from wellhead to well-bottom must be conducted in order to increase the economic performance (Jacobson 2009; Sun et al. 2017b). What is worth to stress is that the wet steam (a mixture of steam and water) is always selected as the thermal carrier due to low cost and high economic efficiency (Sun et al. 2017c).

Ramey (1962) proposed an equation for wet steam temperature estimation based on the energy balance equation. However, their energy balance equation was built upon incompressible fluid. Raymond (1969) presented an improved model that can be used for temperature estimation. Then, a series of works were done on modeling of wet steam flow in the wellbores (Eickmeier et al. 1970; Alves et al. 1992; Hasan and Kabir 1994, 1996, 2012; Hasan et al. 2009; Pourafshary et al. 2009; Livescu et al. 2010; Bahonar and Azaiez 2011a, b; Mao and Harvey 2013; Gu et al. 2014; Sivaramkrishnan et al. 2015).

However, the pressure and temperature of the wet steam are in function relationship. That is to say the temperature can be obtained when the pressure is known, which is different from supercritical water. Zhou (2010) and Xu (2011) proposed models for estimating superheated steam flow in the vertical wells and obtained the pressure and temperature profiles by numerical methods (de Almeida et al. 2017). $\mathrm{Xu}$ et al. (2013) added some oil displacement mechanisms of superheated steam to previous models (Fan et al. 2016). Sun et al. (2017c) proposed an novel model by taking the effect of frictional work on fluid temperature into consideration, which laid a solid foundation for following studies (Sun et al. 2017d, e). Gu et al. (2015) proposed a basic model for single-phase fluid flow in the horizontal section of the wellbores (Dong et al. 2014, 2016). Sun et al. (2017f) improved Dong et al.'s model by modifying the energy balance equation. As a result, the scope of application of the multi-component thermal fluid flow model in horizontal wells was extended to a wider range of injection rate. Then, flow behaviors of saturated steam in parallel or concentric dual-tubing wells were revealed by Wei (2015) and Gu (2016). Based mainly on Wei and Gu et al.'s works, Sun et al. $(2017 \mathrm{~g}, \mathrm{~h}, \mathrm{i})$ conducted a series of studies on superheated fluid (superheated steam or multi-component thermal fluid) flow in parallel or concentric dual-tubing wells. They found out that heat exchange inside the wellbores has an obvious influence on thermophysical properties of superheated fluid in the integral joint tubing and annuli or in the main tubing and auxiliary tubing.

However, these previous works were focused on superheated steam (or multi-component thermal fluid), which cannot be used to analyze the flow behaviors of SCW in wellbores. At present, the study on SCW flow in wellbores was very limited. This paper moves one step forward to develop a numerical model for simulating SCW flow in offshore wellbores. There are mainly three contributions of this paper to the existing body of the literature: (1) a numerical model is developed for SCW flow in offshore wells with consideration of turbulent flow of seawater. (2) Type curves of SCW flow in offshore wells were obtained by finite difference method on space and iteration technique. (3) Effect of injection parameters on the profiles of thermophysical properties of SCW in offshore wellbores was discussed in detail.

\section{Model description}

\section{General assumptions}

The flow channel of SCW from wellhead to well-bottom is shown in Fig. 1. Besides, some basic assumptions are made in order to establish the model, as shown below (Sun et al. 2017j):

1. The injection parameters of SCW at platform are constant during the whole injection process.

2. Heat transfer rate from SCW to the outside wall of riser/ cement sheath is steady state.

3. Thermophysical properties of seawater are independent from well depth.

4. Heat transfer rate from the outside wall of the cement sheath to formation is transient state.

5. Thermophysical properties of SCW remain unchanged as it flows from the platform to the sea surface.

\section{Governing equations of the mathematical model}

The development of the governing equations of SCW flow in wellbores is based on the theory proposed by previous

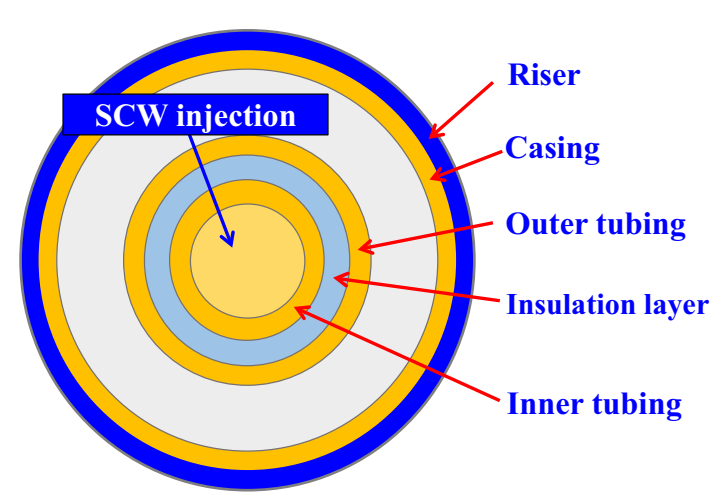

Fig. 1 A schematic of SCW flow in offshore wells 
researchers (Gu et al. 2014; Dong et al. 2016; Wei 2015; Sun et al. 2018a, b, c, d, e, f, g, h).

Firstly, an equation describing the mass change process is developed. The gradient of mass flow rate in the vertical offshore tube is equal to zero.

$\frac{\mathrm{d} w_{\mathrm{SCW}}}{\mathrm{d} z}=\pi r_{a i}^{2} \frac{\mathrm{d}\left(\rho_{\mathrm{SCW}} v_{\mathrm{SCW}}\right)}{\mathrm{d} z}=0$

Based on the energy conservation law (Sun et al. 2018i), the heat transfer rate from wellbore to seawater/formation should be equal to the total energy change in SCW in wellbores. The energy balance equation can be expressed as:

$\frac{\mathrm{d} Q_{\mathrm{SCW}}}{\mathrm{d} z}=-w_{\mathrm{SCW}} \frac{\mathrm{d} h_{\mathrm{SCW}}}{\mathrm{d} z}-w_{\mathrm{SCw}} \frac{\mathrm{d}}{\mathrm{d} z}\left(\frac{v_{\mathrm{SCW}}^{2}}{2}\right)+w_{\mathrm{SCW}} g \cos \theta$

where $Q_{\mathrm{SCW}}$ denotes the heat transfer rate from SCW to seawater/formation (Willhite 1967; Cheng et al. 2012; Liu 2013; Huang et al. 2015) (J/s).

The flowing process of SCW in the vertical offshore tube is subjected to the law of momentum conservation.

$\pi r_{a i}^{2} \mathrm{~d} p_{\mathrm{SCW}}=\rho_{\mathrm{SCW}} \pi r_{a i}^{2} g \cos \theta \mathrm{d} z-f-\pi r_{a i}^{2} \mathrm{~d}\left(\rho_{\mathrm{SCW}} v_{\mathrm{SCW}}^{2}\right)$

where $f$ denotes the shear force (Yuan 1982) (N).

\section{Numerical solution of the mathematical model}

In order to obtain the numerical solutions of the model, the governing equations are expressed in the form of difference equations, as expressed below:

$$
\begin{aligned}
f\left(T_{\mathrm{SCW}, \text { out }}\right)= & \frac{q_{\mathrm{SCW}, \text { out }}+q_{\mathrm{SCW}, \text { in }}}{2}+w_{\mathrm{SCW}} \frac{\left(h_{\mathrm{SCW}, \text { out }}-h_{\mathrm{SCW}, \text { in }}\right)}{\Delta z} \\
& +w_{\mathrm{SCW}} \frac{d}{\Delta z}\left(\frac{v_{\mathrm{SCW}, \text { out }}^{2}}{2}-\frac{v_{\mathrm{SCW}, \text { in }}^{2}}{2}\right)-w_{\mathrm{SCW}} g \cos \theta
\end{aligned}
$$

$$
\begin{aligned}
f\left(p_{\mathrm{SCW}, \text { out }}\right)= & \pi r_{\mathrm{ai}}^{2}\left(p_{\mathrm{SCW}, \text { out }}-p_{\mathrm{SCW}, \text { in }}\right) \\
& -\pi r_{\mathrm{ai}}^{2} g \cos \theta \frac{\rho_{\mathrm{SCW}, \text { out }}+\rho_{\mathrm{SCW}, \text { in }}}{2} \Delta z \\
& +\tau_{f}+\pi r_{\mathrm{ai}}^{2}\left(\rho_{\mathrm{SCW}, \text { out }} v_{\mathrm{SCW}, \text { out }}^{2}-\rho_{\mathrm{SCW}, \text { in }} v_{\mathrm{SCW}, \text { in }}^{2}\right)
\end{aligned}
$$

The model is solved under the boundary condition. The boundary condition (injection pressure and temperature conditions) at the platform is shown below:

$$
\left\{\begin{array}{l}
p(\text { wellhead })=p_{0} \\
T(\text { wellhead })=T_{0}
\end{array}\right.
$$

For a small segment, the injection values at the inlet surface is assumed to be given. Therefore, the outlet values are calculated based on the difference equations shown above. Next, the calculated values at the outlet surface are regared as new input values of the following segment, and the same calculation method is adopted. Finally, the entire distributions of pressure and temperature values along the offshore tube are obtained. In conclusion, the model is solved with straight forward numerical method.

A calculation flowchart for the above discussion is presented in Fig. 2.

\section{Results and discussion}

\section{Type curve analysis}

Based on the discussion above, the obtained values are shows as curves for discussion. The injection pressure, temperature and mass flow rate of SCW at wellhead are $23 \mathrm{MPa}, 700 \mathrm{~K}$ and $216 \mathrm{t} / \mathrm{d}$. The other basic parameters used for calculation are shown in Table 1. The predicted results from the model are shown in Fig. 3.

It is observed from Fig. 3a that: (a) The value of pressure gradient in the seawater section of the wellbores (from 0 to $150 \mathrm{~m}$ ) is close to the that in the formation section of the wellbores (from 150 to $1350 \mathrm{~m}$ ). Therefore, it is concluded that the effect of seawater on SCW pressure in wellbores is negligible. (b) SCW pressure increases with well depth. This is because the SCW density increases with well depth, as shown in Fig. 3b.

It is observed from Fig. 3b that: (a) SCW density increases with well depth. This is because there always exists heat loss from SCW to seawater/formation, which causes the decrease in SCW volume. Therefore, the SCW density increases with decreasing of SCW temperature. (b) There exists a turning point where SCW reaches the seabed (the depth of $150 \mathrm{~m}$ ). The gradient of density curve in the seawater section of the wellbores is larger than that in the formation section of the wellbores. This is because the SCW temperature drops faster in the seawater section of the wellbores, as shown in Fig. 3c.

It is observed from Fig. 3c that: (a) SCW temperature always decreases with well depth no matter in the seawater section of the wellbores or in the formation section of the wellbores. This is because there always exists a temperature difference between SCW in wellbores and seawater/formation, which leads to 


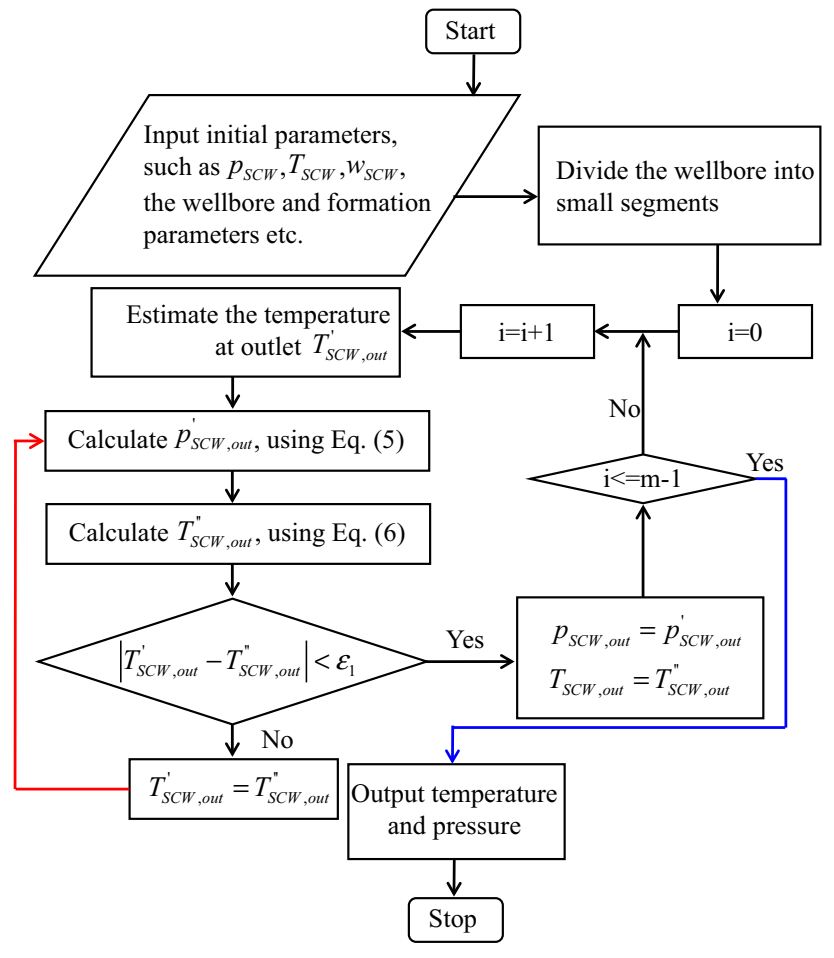

Fig. 2 Numerical solution for the mathematical model

Table 1 Basic parameters used for calculation

\begin{tabular}{lll}
\hline Parameter & Unit & Value \\
\hline Inside radius of inner tubing $\left(r_{a i}\right)$ & $\mathrm{m}$ & 0.0380 \\
Outside radius of inner tubing $\left(r_{a o}\right)$ & $\mathrm{m}$ & 0.0440 \\
Inside radius of outer tubing $\left(r_{b i}\right)$ & $\mathrm{m}$ & 0.0509 \\
Outside radius of outer tubing $\left(r_{b o}\right)$ & $\mathrm{m}$ & 0.0572 \\
Inside radius of casing $\left(r_{c i}\right)$ & $\mathrm{m}$ & 0.0807 \\
Outside radius of casing $\left(r_{c o}\right)$ & $\mathrm{m}$ & 0.0889 \\
Outside radius of the wellbore $\left(r_{\text {cem }}\right)$ & $\mathrm{m}$ & 0.1236 \\
Outside radius of the riser $\left(r_{\text {riser }}\right)$ & $\mathrm{m}$ & 0.0978 \\
Riser length $\left(L_{\text {sea }}\right)$ & $\mathrm{m}$ & 160 \\
Mud segment length $\left(L_{\text {mud }}\right)$ & $\mathrm{m}$ & 10 \\
Depth of seawater $\left(h_{\text {sea }}\right)$ & $\mathrm{m}$ & 150 \\
Well depth $\left(h_{\text {well }}\right)$ & $\mathrm{m}$ & 1200 \\
\hline
\end{tabular}

heat conduction of the wellbore/seawater system. (b) SCW temperature decreases rapidly in the seawater section of the wellbores. This is because the seawater is always flowing, which breaks the temperature field around the wellbores. Therefore, the temperature difference between wellbore and seawater is larger than that between wellbore and formation, which causes a higher heat loss rate in the seawater section of the wellbores. In conclusion, in order to obtain a better oil recovery effect, high-quality insulation material should
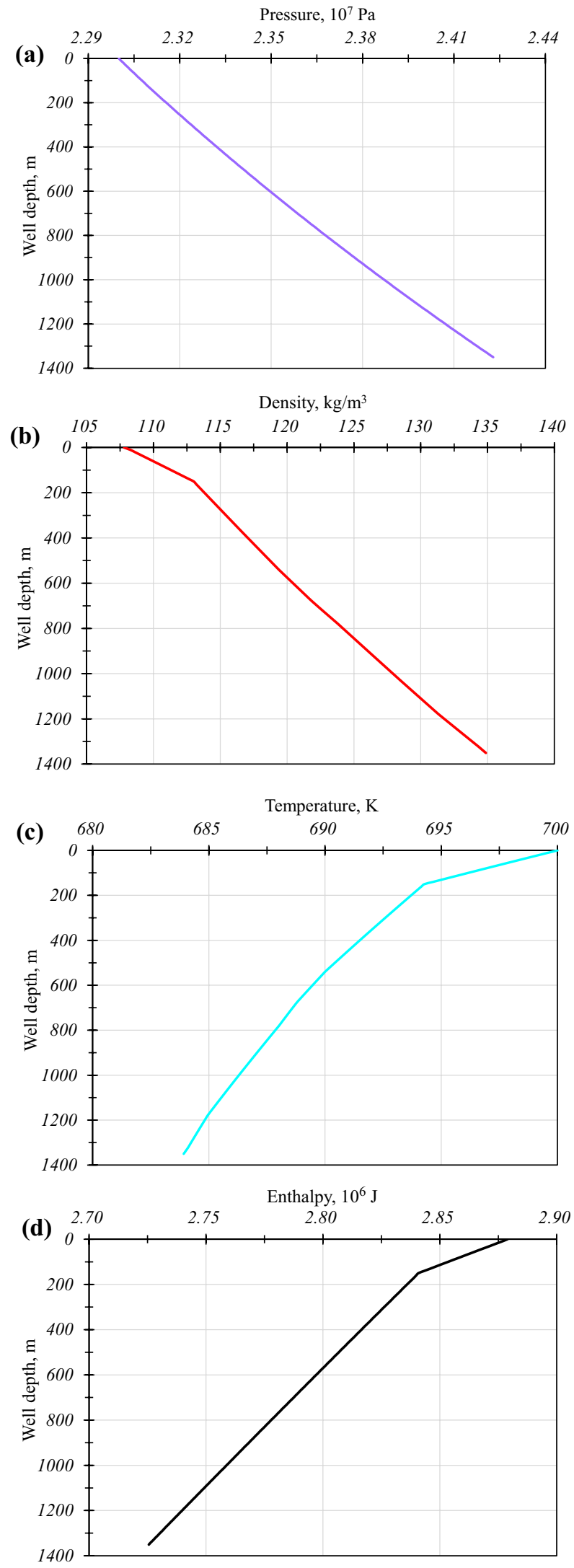

Fig. 3 Type curve of SCW flow in offshore wellbores 
be adopted to decrease the heat loss rate in the seawater section of wellbores.

It is observed from Fig. 3d that: (a) SCW enthalpy decreases with well depth. This is because there always exists heat loss from SCW to seawater/formation due to temperature difference. (b) The enthalpy gradient in the seawater section of the wellbores is larger than that in the formation section of the wellbores.

In conclusion, effect of seawater on the profiles of SCW pressure in wellbores is negligible. However, the flow of seawater results in a rapid decline in the temperature/enthalpy of SCW in wellbores.

\section{Sensitivity analysis}

\section{Injection rate}

In this section, effect of injection rate on the profiles of thermophysical properties of SCW is discussed in detail. Different injection rates $(90,140,190,240,290$ and $340 \mathrm{t} / \mathrm{d})$ input into the model under the condition that the injection pressure and temperature are kept unchanged. The predicted results are shown in Fig. 4.

It is observed from Fig. 4a that SCW pressure decreases with increasing of injection rate. In fact, the form of SCW pressure curve is the comprehensive effect of injection rate and SCW density. The increase in injection rate leads to pressure drop, while the increase in SCW density leads to pressure increase.

It is observed from Fig. $4 \mathrm{~b}$ that (a) the density gradient in the seawater section of wellbores is always larger than that in the formation section of wellbores. (b) SCW density increases rapidly when the injection rate is small. Taken $90 \mathrm{t} / \mathrm{d}$ as an example, the SCW density has an increase of $72.03 \%$ from wellhead to well-bottom. However, it is $13.45 \%$ when the injection rate is $340 \mathrm{t} / \mathrm{d}$. This is because the SCW temperature drops rapidly when the injection rate is small, which causes the rapid decrease in SCW volume.

It is observed from Fig. $4 \mathrm{c}$ that (a) the temperature gradient in the seawater section of wellbores is always larger than that in the formation section of wellbores under various values of injection rate. (b) SCW temperature increases with increasing of injection rate. (c) When the injection rate is large enough (larger than $240 \mathrm{t} / \mathrm{d}$ ), the rate of temperature rise decreases.

It is observed from Fig. $4 \mathrm{~d}$ that (a) the enthalpy gradient in the seawater section of wellbores is always larger than that in the formation section of wellbores under various values of injection rate. (b) SCW enthalpy increases with increasing of injection rate. (c) When the injection rate is large enough (larger than $240 \mathrm{t} / \mathrm{d}$ ), the rate of enthalpy rise decreases.

In conclusion, heat loss is the dominant factor of physical parameter distribution in wellbores. When the injection rate
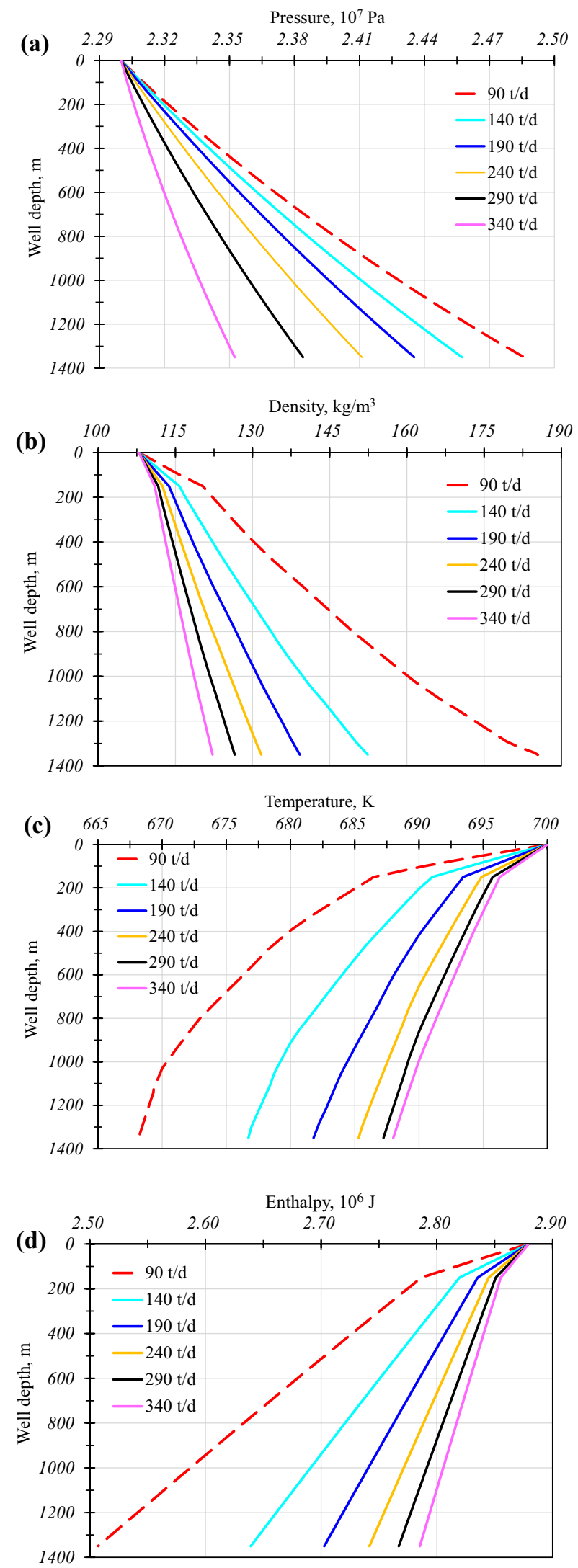

Fig. 4 Effect of injection rate on the profiles of thermophysical properties of SCW in offshore wellbores: a SCW pressure; b SCW density; c SCW temperature; d SCW enthalpy 
is relatively small, heat loss results in a rapid decrease in temperature and enthalpy, which causes the rapid increase in SCW density. As a result, SCW pressure increases rapidly with well depth.

\section{Injection pressure}

In this section, effect of injection pressure on the profiles of thermophysical properties of SCW is discussed in detail. Different injection pressure $(23,24,25,26$ and $27 \mathrm{MPa})$ is input into the model under the condition that the injection rate and temperature are kept unchanged. The predicted results are shown in Fig. 5.

It is observed from Fig. 5a that effect of seawater on SCW pressure is negligible under various values of injection pressure. Pressure gradient in the seawater section of wellbores is almost equal to that in the formation section of wellbores.

It is observed from Fig. 5b that (a) the density gradient in the seawater section of wellbores is always larger than that in the formation section of the wellbores under various values of injection pressure. (b) SCW density increases with increasing of SCW pressure. This is because the volume becomes smaller under a higher pressure. As a result, the flow velocity decreases with increasing of density.

It is observed from Fig. 5c that (a) the temperature gradient in the seawater section of wellbores is always larger than that in the formation section of wellbores under various values of injection pressure. (b) SCW temperature increases with increasing of injection pressure. This is because when the injection pressure is small, the SCW density is small. At this point, heat loss has an obvious influence on temperature drop of SCW with a small density.

It is observed from Fig. 5d that (a) the enthalpy gradient in the seawater section of wellbores is always larger than that in the formation section of wellbores under various values of injection pressure. (b) The SCW enthalpy decreases with increasing of injection pressure. This is because the pressure is decreasing while the injection temperature is kept unchanged at wellhead.

In conclusion, heat loss has an obvious influence on temperature drop when SCW is sparse in volume. In order to bring more heat to well-bottom (reservoir condition), a smaller injection pressure is recommended.

\section{Injection temperature}

In this section, effect of injection temperature on the profiles of thermophysical properties of SCW is discussed in detail. Different injection temperature $(690,700,710,720$, 730 and $740 \mathrm{~K}$ ) is input into the model under the condition that the injection rate and pressure are kept unchanged. The predicted results are shown in Fig. 6.
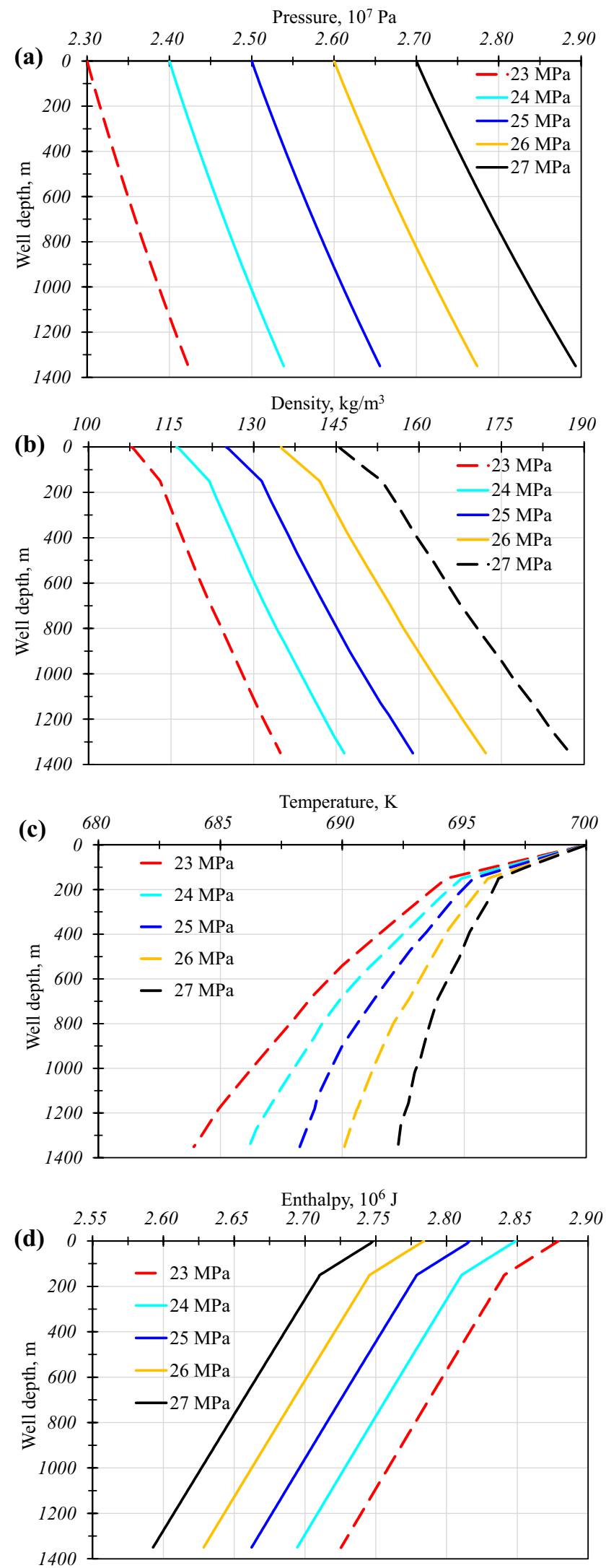

Fig. 5 Effect of injection pressure on the profiles of thermophysical properties of SCW in offshore wellbores: a SCW pressure; b SCW density; c SCW temperature; $\mathbf{d}$ SCW enthalpy 
It is observed from Fig. 6a that the SCW pressure decreases with increasing of injection temperature. This is because SCW density decreases with increasing of injection temperature, as shown in Fig. 6b.

It is observed from Fig. $6 \mathrm{~b}$ that (a) the density gradient in the seawater section of wellbores is always larger than that in the formation section of the wellbores under various values of injection temperature. (b) The SCW density decreases with increasing of injection temperature. This is because the SCW volume per unit mass increases under the condition that the SCW pressure is kept unchanged.

It is observed from Fig. $6 c, d$ that (a) the temperature/ enthalpy gradient in the seawater section of wellbores is always larger than that in the formation section of wellbores under various values of injection temperature. (b) The SCW temperature increases with increasing of injection temperature. As a result, SCW enthalpy increases with increasing of temperature, as shown in Fig. 6d.

\section{Conclusions}

In this paper, a series of works were done to study the effect of seawater on SCW flow in offshore wellbores. Besides, effect of injection parameters of the profiles of thermophysical properties of SCW in wellbores was discussed in detail. Some main findings are summarized below:

(a) Effect of seawater on the profiles of SCW pressure in wellbores is negligible. However, the flow of seawater results in a rapid decline in the temperature/enthalpy of SCW in wellbores.

(b) Heat loss is the dominant factor of physical parameter distribution in wellbores. When the injection rate is relatively small, heat loss results in a rapid decrease in temperature and enthalpy, which causes the rapid increase in SCW density. As a result, SCW pressure increases rapidly with well depth.

(c) Heat loss has an obvious influence on temperature drop when SCW is sparse in volume. In order to bring more heat to well-bottom (reservoir condition), a smaller injection pressure is recommended.

(d) The SCW pressure decreases with increasing of injection temperature. This is because SCW density decreases with increasing of injection temperature.

Acknowledgements The authors wish to thank the National Basic Research Program of China (2015CB250900), the Program for New Century Excellent Talents in University (Grant No.NCET-13-1030), the National Natural Science Foundation of China (Grant No.40974055), the National Science and Technology Major Projects of China (2016ZX05039 and 2016ZX05042), the National Natural fund of China
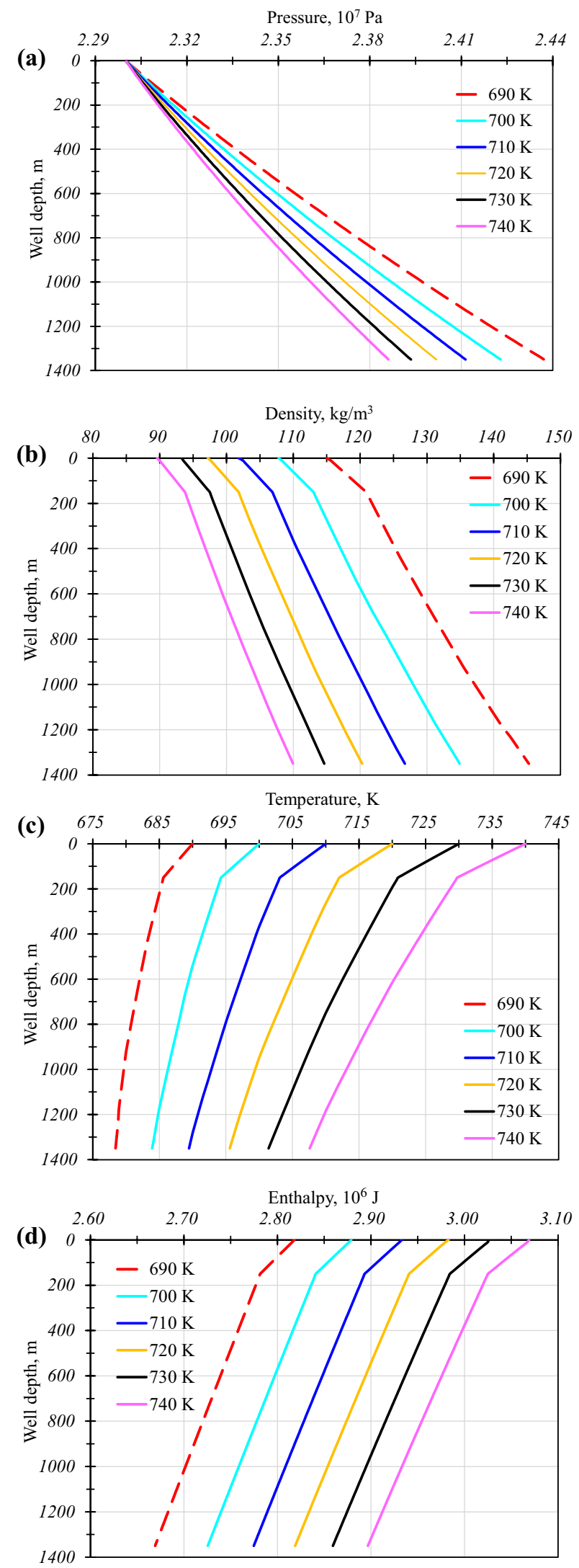

Fig. 6 Effect of injection temperature on the profiles of thermophysical properties of SCW in offshore wellbores: a SCW pressure; b SCW density; c SCW temperature; d SCW enthalpy 
(51490654), and the Science Foundation of China University of Petroleum, Beijing (No.C201605).

Open Access This article is distributed under the terms of the Creative Commons Attribution 4.0 International License (http://creativeco mmons.org/licenses/by/4.0/), which permits unrestricted use, distribution, and reproduction in any medium, provided you give appropriate credit to the original author(s) and the source, provide a link to the Creative Commons license, and indicate if changes were made.

\section{Appendix: Physical property of SCW}

The calculation tables for SCW properties can be found online: http://webbook.nist.gov/chemistry/fluid/.

\section{References}

Akhmedzhanov TK, Nuranbayeva BM, Gussenov I, Ismagilova LT (2017) Enhanced oil recovery and natural bitumen production through the use of sinusoidal wells and solar thermal method. J Pet Sci Eng 159:506-512

Alves IN, Alhanati FJS, Shoham O (1992) A unified model for predicting flowing temperature distribution in wellbores and pipelines. SPE Prod Eng 7(4):363-367

Bahonar M, Azaiez J (2011a) Transient non isothermal fully coupled wellbore/reservoir model for gas-well testing, part 1: modelling. J Can Pet Technol 50(9-10):37-50

Bahonar M, Azaiez J (2011b) Transient non isothermal fully coupled wellbore/reservoir model for gas-well testing, part 2: applications. J Can Pet Technol 50(9):51-70

Cheng WL, Huang YH, Liu N et al (2012) Estimation of geological formation thermal conductivity by using stochastic approximation method based on well-log temperature data. Energy 38:21-30

Coskuner G, Naderi K, Babadagli T (2015) An enhanced oil recovery technology as a follow up to cold heavy oil production with sand. J Pet Sci Eng 133:475-482

de Almeida RV, Rahnema H, McMillan MD (2017) Wellbore modeling for hybrid steam-solvent processes. Fuel 188:50-60

Dong XH, Liu HQ, Zhang ZX et al (2014) The flow and heat transfer characteristics of multi-thermal fluid in horizontal wellbore coupled with flow in heavy oil reservoirs. J Pet Sci Eng 122:56-68

Dong X, Liu H, Hou J, Zhang Z, Chen Z (2015) Multi-thermal fluid assisted gravity drainage process: a new improved-oil-recovery technique for thick heavy oil reservoir. J Pet Sci Eng 133:1-11

Dong XH, Liu HQ, Hou JR, Chen ZX (2016) Transient fluid flow and heat transfer characteristics during co-injection of steam and condensable gases in horizontal wells. J China Univ Pet (Ed Nat Sci) 40(2): 105-114

Eickmeier J, Ersoy D, Ramey H, Eickmeier J, Ersoy D, Ramey H (1970) Wellbore temperatures and heat losses during production or injection operations. J Can Pet Technol 9(2):6

Fan ZF, He CG, Xu AZ (2016) Calculation model for on-way parameters of horizontal wellbore in the superheated steam injection. Petrol Explor Dev 43(5):798-805

$\mathrm{Gu} \mathrm{H}$ (2016) Mass and heat transfer model and application of wellbore/ formation coupling during steam injection in SAGD process. Doctoral dissertation, China University of Petroleum, Beijing

Gu H, Cheng L, Huang S, Du B, Hu C (2014) Prediction of thermophysical properties of saturated steam and wellbore heat losses in concentric dual-tubing steam injection well. Energy 75:419-429
Gu H, Cheng LS, Huang SJ et al (2015) Thermo-physical properties estimation and performance analysis of superheated-steam injection in horizontal wells considering phase change. Energy Convers Manag 99:119-131

Hasan AR, Kabir CS (1994) Aspects of wellbore heat transfer during two-phase flow. SPE Prod Facil 9(3):211-216

Hasan AR, Kabir CS (1996) A mechanistic model for computing fluid temperature profiles in gas-lift wells. SPE Prod Facil 11(3):179-185

Hasan AR, Kabir CS (2012) Wellbore heat-transfer modeling and applications. J Pet Sci Eng 86-87:127-136

Hasan AR, Kabir CS, Wang X (2009) A robust steady-state model for flowing-fluid temperature in complex wells. SPE Prod Oper 24(24):269-276

Huang SJ, Li Q, Cheng LS (2015) An evaluation model on alongpipe thermal parameters of multi-component heat fluid injected in offshore reservoirs. J Southwest Pet Univ Sci Technol 37:91-97

Jacobson MZ (2009) Review of solutions to global warming, air pollution, and energy security. Energy Environ Sci 2(2):148-173

Liu HQ (2013) Principle and design of thermal oil recovery. Petroleum Industry Press, Beijing

Livescu S, Durlofsky LJ, Aziz K, Ginestra JC (2010) A fully-coupled thermal multiphase wellbore flow model for use in reservoir simulation. J Pet Sci Eng 71(3):138-146

Mao D, Harvey A (2013) Transient-nonisothermal-multiphase-wellbore-model development with phase change and its application to producer wells. SPE J 18(6):1169-1180

Marx JW, Langenheim RH (1959) Reservoir heating by hot fluid injection petroleum transactions. AIME 216:312-315

Mullakaev MS, Abramov VO, Abramova AV (2017) Ultrasonic automated oil well complex and technology for enhancing marginal well productivity and heavy oil recovery. J Pet Sci Eng 159:1-7

Nian Y-L, Cheng W-L (2017) Insights into heat transport for thermal oil recovery. J Pet Sci Eng 151:507-521

Pourafshary P, Varavei A, Sepehrnoori K, Podio A (2009) A compositional wellbore/reservoir simulator to model multiphase flow and temperature distribution. J Pet Sci Eng 69(1):40-52

Ramey HJ (1962) Wellbore heat transmission. J Pet Technol 14(4):427-435

Raymond LR (1969) Temperature distribution in a circulating drilling fluid. J Pet Technol 21(3):333-341

Rego FB, Botechia VE, Schiozer DJ (2017) Heavy oil recovery by polymer flooding and hot water injection using numerical simulation. J Pet Sci Eng 153:187-196

Sheikholeslami M, Bhatti MM (2017) Forced convection of nanofluid in presence of constant magnetic field considering shape effects of nanoparticles. Int J Heat Mass Transf 111:1039-1049

Sheikholeslami M, Ganji DD (2014) Ferrohydrodynamic and magnetohydrodynamic effects on ferrofluid flow and convective heat transfer. Energy 75(1):400-410

Sheikholeslami M, Ganji DD (2016) Heat transfer enhancement in an air to water heat exchanger with discontinuous helical turbulators: experimental and numerical studies. Energy 116(Part 1):341-352

Sheikholeslami M, Rokni HB (2017a) Simulation of nanofluid heat transfer in presence of magnetic field: a review. Int J Heat Mass Transf 115(Part B):1203-1233

Sheikholeslami M, Rokni HB (2017b) Melting heat transfer influence on nanofluid flow inside a cavity in existence of magnetic field. Int J Heat Mass Transf 114:517-526

Sheikholeslami M, Rokni HB (2018) Numerical simulation for impact of Coulomb force on nanofluid heat transfer in a porous enclosure in presence of thermal radiation. Int J Heat Mass Transf 118:823-831

Sheikholeslami M, Sadoughi M (2017) Mesoscopic method for MHD nanofluid flow inside a porous cavity considering various shapes of nanoparticles. Int J Heat Mass Transf 113:106-114 
Sheikholeslami M, Sadoughi MK (2018) Simulation of CuO-water nanofluid heat transfer enhancement in presence of melting surface. Int J Heat Mass Transf 116:909-919

Sheikholeslami M, Seyednezhad M (2017) Nanofluid heat transfer in a permeable enclosure in presence of variable magnetic field by means of CVFEM. Int J Heat Mass Transf 114:1169-1180

Sheikholeslami M, Seyednezhad M (2018) Simulation of nanofluid flow and natural convection in a porous media under the influence of electric field using CVFEM. Int J Heat Mass Transf 120:772-781

Sheikholeslami M, Shehzad SA (2017a) CVFEM for influence of external magnetic source on $\mathrm{Fe}_{3} \mathrm{O}_{4}-\mathrm{H}_{2} \mathrm{O}$ nanofluid behavior in a permeable cavity considering shape effect. Int J Heat Mass Transf 115(Part A):180-191

Sheikholeslami M, Shehzad SA (2017b) Magnetohydrodynamic nanofluid convective flow in a porous enclosure by means of LBM. Int J Heat Mass Transf 113:796-805

Sheikholeslami M, Shehzad SA (2018a) CVFEM simulation for nanofluid migration in a porous medium using Darcy model. Int J Heat Mass Transf 122:1264-1271

Sheikholeslami M, Shehzad SA (2018b) Simulation of water based nanofluid convective flow inside a porous enclosure via nonequilibrium model. Int J Heat Mass Transf 120:1200-1212

Sheikholeslami M, Shehzad SA (2018c) Numerical analysis of $\mathrm{Fe}_{3} \mathrm{O}_{4}-\mathrm{H}_{2} \mathrm{O}$ nanofluid flow in permeable media under the effect of external magnetic. Int J Heat Mass Transf 118:182-192

Sheikholeslami M, Gorji-Bandpy M, Ganji DD (2013) Numerical investigation of MHD effects on $\mathrm{Al}_{2} \mathrm{O}_{3}$-water nanofluid flow and heat transfer in a semi-annulus enclosure using LBM. Energy 60(1):501-510

Sheikholeslami M, Hayat T, Alsaedi A (2017) On simulation of nanofluid radiation and natural convection in an enclosure with elliptical cylinders. Int J Heat Mass Transf 115(Part A):981-991

Sheikholeslami M, Darzi M, Sadoughi MK (2018) Heat transfer improvement and pressure drop during condensation of refrigerant-based nanofluid: an experimental procedure. Int J Heat Mass Transf 122:643-650

Sivaramkrishnan K, Huang B, Jana AK (2015) Predicting wellbore dynamics in a steam-assisted gravity drainage system: numeric and semi-analytic model, and validation. Appl Therm Eng 91:679-686

Sun FR, Yao YD, Li XF (2017a) Effect of gaseous $\mathrm{CO}_{2}$ on superheated steam flow in wells. Eng Sci Technol Int J 20(6):1579-1585

Sun FR, Yao YD, Li XF, Yu PL, Ding GY, Zou M (2017b) The flow and heat transfer characteristics of superheated steam in offshore wells and analysis of superheated steam performance. Comput Chem Eng 100:80-93

Sun FR, Yao YD, Chen MQ, Li XF, Zhao L, Meng Y, Sun Z, Zhang T, Feng D (2017c) Performance analysis of superheated steam injection for heavy oil recovery and modeling of wellbore heat efficiency. Energy 125:795-804

Sun FR, Yao YD, Li XF, Li H, Chen G, Sun Z (2017d) A numerical study on the non-isothermal flow characteristics of superheated steam in ground pipelines and vertical wellbores. J Pet Sci Eng 159:68-75

Sun FR, Yao YD, Li XF, Zhao L (2017e) Type curve analysis of superheated steam flow in offshore horizontal wells. Int J Heat Mass Transf 113:850-860

Sun FR, Yao YD, Li XF, Zhao L, Ding GY, Zhang XJ (2017f) The mass and heat transfer characteristics of superheated steam coupled with non-condensing gases in perforated horizontal wellbores. J Pet Sci Eng 156:460-467

Sun FR, Yao YD, Li XF, Tian J, Zhu GJ, Chen ZM (2017g) The flow and heat transfer characteristics of superheated steam in concentric dual-tubing wells. Int $\mathrm{J}$ Heat Mass Transf 115:1099-1108

Sun FR, Yao YD, Li XF, Yu PL, Zhao L, Zhang Y (2017h) A numerical approach for obtaining type curves of superheated multicomponent thermal fluid flow in concentric dual-tubing wells. Int J Heat Mass Transf 111:41-53

Sun FR, Yao YD, Li XF (2017i) Numerical simulation of superheated steam flow in dual-tubing wells. J Pet Explor Prod Technol. https://doi.org/10.1007/s13202-017-0390-7

Sun FR, Yao YD, Li XF (2017j) Effect analysis of non-condensable gases on superheated steam flow in vertical single-tubing steam injection pipes based on the real gas equation of state and the transient heat transfer model in formation. J Pet Explor Prod Technol. https://doi.org/10.1007/s13202-017-0419-y

Sun FR, Yao YD, Li XF (2018a) The heat and mass transfer characteristics of superheated steam coupled with non-condensing gases in horizontal wells with multi-point injection technique. Energy 143:995-1005

Sun FR, Yao YD, Li XF, Li GZ, Chen ZL, Chang YC, Cao M, Han S, Lv CH, Feng D, Sun Z (2018b) Effect of flowing seawater on supercritical $\mathrm{CO}_{2}$-superheated water mixture flow in an offshore oil well considering the distribution of heat generated by the work of friction. J Pet Sci Eng 162:460-468

Sun FR, Yao YD, Li XF, Li GZ, Miao YN, Han S, Chen ZL (2018c) Flow simulation of the mixture system of supercritical $\mathrm{CO}_{2}$ and superheated steam in toe-point injection horizontal wellbores. J Pet Sci Eng 163:199-210

Sun FR, Yao YD, Li XF, Li GZ, Sun Z (2018d) A numerical model for predicting distributions of pressure and temperature of superheated steam in multi-point injection horizontal wells. Int J Heat Mass Transf 121:282-289

Sun FR, Yao YD, Li XF, Li GZ, Huang L, Liu H, Chen ZL, Liu Q, Liu WY, Cao M, Han S (2018e) Exploitation of heavy oil by supercritical $\mathrm{CO}_{2}$ : effect analysis of supercritical $\mathrm{CO}_{2}$ on $\mathrm{H}_{2} \mathrm{O}$ at superheated state in integral joint tubing and annuli. Greenh Gases Sci Technol. https://doi.org/10.1002/ghg.1764

Sun FR, Yao YD, Li XF, Li GZ, Liu Q, Han S, Zhou YJ (2018f) Effect of friction work on key parameters of steam at different state in toe-point injection horizontal wellbores. J Pet Sci Eng 164:655-662

Sun FR, Yao YD, Li XF (2018g) The heat and mass transfer characteristics of superheated steam in horizontal wells with toepoint injection technique. J Pet Explor Prod Technol. https://doi. org/10.1007/s13202-017-0407-2

Sun FR, Yao YD, Li XF, Li GZ, Han S, Liu Q, Liu WY (2018h) Type curve analysis of multi-phase flow of multi-component thermal fluid in toe-point injection horizontal wells considering phase change. J Petrol Sci Eng 165:557-566

Sun FR, Yao YD, Li GZ, Li XF, Chen MQ, Chen G, Zhang T (2018i) Analysis of superheated steam performance in offshore concentric dual-tubing wells. J Petrol Sci Eng. https://doi.org/10.1016/j.petro 1.2018.03.108

Telmadarreie A, Trivedi J (2017) Evaluation of foam generated with the hydrocarbon solvent for extra-heavy oil recovery from fractured porous media: pore-scale visualization. J Pet Sci Eng 157:1170-1178

Wei SL (2015) Flow mechanism and production practice for the integral process of SAGD using horizontal well pairs (Doctoral Dissertation). China University of Petroleum, Beijing

Willhite GP (1967) Over-all heat transfer coefficients in steam and hot water injection wells. J Pet Technol 19(05):607-615

Xu KQ (2011) Technology and practice of superheated steam huff and puff in heavy oil reservoir. Petroleum Industry Press, Beijing

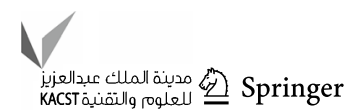


Xu AZ, Mu LX, Fan ZF, Wu XH, Zhao L, Bo B et al (2013) Mechanism of heavy oil recovery by cyclic superheated steam stimulation. J Pet Sci Eng 111:197-207

Yuan EX (1982) Engineering fluid mechanics. Petroleum Industry Press, Beijing, pp 87-163

Zhou TY (2010) Mechanism study of heavy oil exploitation with superheated steam injection. Doctoral dissertation, China University of Petroleum, Beijing
Zhou X, Yuan Q, Peng X, Zeng F, Zhang L (2018) A critical review of the $\mathrm{CO}_{2}$ huff ' $\mathrm{n}$ ' puff process for enhanced heavy oil recovery. Fuel 215(1):813-824

Publisher's Note Springer Nature remains neutral with regard to jurisdictional claims in published maps and institutional affiliations. 